\title{
High Thrust-to-Power Annular Engine Technology
}

\author{
Michael J. Patterson ${ }^{1}$ and Robert E. Thomas ${ }^{2}$ \\ NASA Glenn Research Center, Cleveland, OH, 44135 \\ Mark W. Crofton ${ }^{3}$ and Jason A. Young ${ }^{4}$ \\ The Aerospace Corporation, El Segundo, CA, 90245 \\ John E. Foster ${ }^{5}$ \\ University of Michigan, Ann Arbor, MI, 48109
}

\begin{abstract}
Gridded ion engines have the highest efficiency and total impulse of any mature electric propulsion technology, and have been successfully implemented for primary propulsion in both geocentric and heliocentric environments with excellent ground/in-space correlation of performance. However, they have not been optimized to maximize thrust-to-power, an important parameter for Earth orbit transfer applications. This publication discusses technology development work intended to maximize this parameter. These activities include investigating the capabilities of a non-conventional design approach, the annular engine, which has the potential of exceeding the thrust-to-power of other EP technologies. This publication discusses the status of this work, including the fabrication and initial tests of a large-area annular engine. This work is being conducted in collaboration among NASA Glenn Research Center, The Aerospace Corporation, and the University of Michigan.
\end{abstract}

\section{Nomenclature}

$\begin{array}{ll}\text { AE } & =\text { Annular Engine } \\ \text { EOT } & =\text { Earth orbit transfer } \\ \text { EP } & =\text { electric propulsion } \\ F & =\text { thrust, N } \\ \text { HERMeS } & =\text { Hall Effect Rocket with Magnetic Shielding } \\ \text { HET } & =\text { Hall-Effect Thruster } \\ I_{s p} & =\text { specific impulse, seconds } \\ \text { NEXT } & =\text { NASA's Evolutionary Xenon Thruster } \\ \text { PG } & =\text { pyrolytic graphite } \\ P_{i n} & =\text { thruster input power, kW (unless otherwise specified) } \\ \text { SEP TDM } & =\text { Solar Electric Propulsion Technology Demonstration Mission } \\ \text { SOA } & =\text { state of the art } \\ \text { TAC } & =\text { The Aerospace Corporation } \\ \text { TRL } & =\text { Technology Readiness Level } \\ V_{b} & =\text { beam voltage, } \mathrm{V} \\ \alpha & =\text { thrust-loss correction factor due to doubly-charged ions } \\ \beta & =\text { thrust-loss correction factor due to beam divergence } \\ \varepsilon_{i} & =\text { discharge losses, W/A }\end{array}$

\footnotetext{
${ }^{1}$ Sr. Technologist, Propulsion Division, 21000 Brookpark Road/MS 301-3, AIAA Sr. Member

${ }^{2}$ Research Engineer, In-Space Propulsion Systems Branch, 21000 Brookpark Road/MS 301-3, AIAA Member

${ }^{3}$ Sr. Scientist, Space Materials Laboratory, M2-341, P.O. Box 92957, Los Angeles, CA 90009, AIAA Sr. Member

${ }^{4}$ Member of Technical Staff, Space Materials Laboratory, M2-341, P.O. Box 92957, Los Angeles, CA 90009

${ }^{5}$ Associate Professor, Department of Nuclear Engineering and Radiological Sciences, 1906 Cooley Building 2355

Bonisteel Boulevard, AIAA Member
} 


\section{Introduction ${ }^{6}$}

$\mathrm{D}$ ESPITE more than 50 years of research and development investment in electrostatic (gridded) ion engine technology, and more than 100 engines presently in operation in space on U.S. commercial and NASA spacecraft, these devices were never optimized for Earth orbit transfer (EOT) operations where maximizing thrustto-power $\left(F / P_{i n}\right)$ is the critical metric. This situation arose for several reasons: little government funding for ion engine orbit transfer R\&D, with investments since the early 1980's targeting high specific impulse planetary science applications; initial application of ion engine technology for Earth space involved on-orbit station-keeping of commercial satellites where high $F / P_{\text {in }}$ was not necessary; Hall-Effect thrusters (HETs) were generally seen as a better solution; and limited available spacecraft power for electric propulsion (EP).

However, improvements in the ion engine $F / P_{\text {in }}$ parameter would yield higher performance than any other EP technology in the $4-12+\mathrm{kW}$ power range, over the broadest obtainable range in specific impulse $\left(I_{s p}\right) .{ }^{1}$ This, in combination with its excellent demonstrated ground/in-space correlation of performance in primary propulsion applications in both geocentric and heliocentric environments, make it an attractive technology option for continued investments.

State of the art (SOA) ion engines have been operated at high thrust density and high total thrust, at levels approaching other high power devices (e.g. HETs). ${ }^{1-5}$ These demonstrations however did not involve purposeful modifications to the technology to optimize performance or the $F / P_{\text {in }}$ parameter. This is because these engines were intentionally designed for operation at low thrust densities for the purpose of achieving extremely long life times, in support of space science missions. A summary of these test results, including maximum thrust, thrust density, power, power density, and peak $F / P_{\text {in }}$ are listed in Table 1 . Notable are the peak thrust and power densities demonstrated over two decades ago $\left(\sim 9 \mathrm{~N} / \mathrm{m}^{2}\right.$ and $\left.\sim 260 \mathrm{~kW} / \mathrm{m}^{2}\right)$ and the peak power demonstrated with the high Technology Readiness Level (TRL) NASA NEXT thruster $(\sim 13.6 \mathrm{~kW})$.

Table 1. Prior demonstrated maximum thrust, thrust density, power, power density, and thrust-to-power ratio for relevant electrostatic (gridded ion) engines.

\begin{tabular}{|c|c|c|c|c|c|}
\hline Engine & $\begin{array}{c}\text { Max. } F, \mathbf{m N} \\
{[\text { Thrust }} \\
\left.\text { Density, } N / \mathbf{m}^{2}\right]\end{array}$ & $\begin{array}{c}\text { Max. Pin, kW } \\
\text { [Power Density, } \\
\text { kW/m²] }\end{array}$ & $\begin{array}{c}\text { Peak } F / P_{\text {in }} \\
\text { (typical), } \\
\text { mN/kW }\end{array}$ & $\begin{array}{c}\text { Corresponding } \\
\text { Specific Impulse, } \\
\text { sec } \\
\end{array}$ & Reference \\
\hline $\begin{array}{c}30 \mathrm{~cm} \\
\text { Divergent }\end{array}$ & 577 [8.92] & 17.1 [264] & 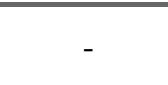 & 4,380 & \multirow{2}{*}{$\begin{array}{c}\text { AIAA-88- } \\
2914\end{array}$} \\
\hline \multirow{5}{*}{$\begin{array}{c}30 \mathrm{~cm} \\
\text { Ring-Cusp }\end{array}$} & $301[4.65]$ & 8.72 [135] & - & 4,125 & \\
\hline & - & - & 56.8 & 1,610 & \multirow{4}{*}{$\begin{array}{c}\text { AIAA-92- } \\
3203\end{array}$} \\
\hline & - & - & 54.1 & 1,830 & \\
\hline & - & - & 52.7 & 1,980 & \\
\hline & - & - & 50.2 & 2,140 & \\
\hline \multirow{12}{*}{$\begin{array}{l}40 \mathrm{~cm} \\
\text { NEXT }\end{array}$} & $466[3.71]$ & $13.6[134]$ & - & 4,670 & \multirow{7}{*}{$\begin{array}{c}\text { AIAA-2006- } \\
4664\end{array}$} \\
\hline & - & - & 47.5 & 2,660 & \\
\hline & - & - & 47.7 & 2,745 & \\
\hline & - & - & 48.3 & 2,755 & \\
\hline & - & - & 48.0 & 2,835 & \\
\hline & - & - & 48.6 & 2,730 & \\
\hline & - & - & 48.7 & 2,785 & \\
\hline & - & - & 47.8 & 2,470 & \multirow{5}{*}{$\begin{array}{c}\text { AIAA-2013- } \\
3891\end{array}$} \\
\hline & - & - & 47.6 & 2,590 & \\
\hline & - & - & 45.0 & 2,860 & \\
\hline & - & - & 43.7 & 3,010 & \\
\hline & - & - & 42.5 & 3,140 & \\
\hline
\end{tabular}

${ }^{6}$ All concepts disclosed in the publication are either covered under U.S. Patent \#8,468,794 ("Electric Propulsion Apparatus", June 25, 2013), or are Patent-Pending filed under both U.S. and International Patent Applications. Assignee: United State Government. 
It is illustrative to compare the peak $F / P_{\text {in }}$ values for SOA ion engines in Table 1 with those demonstrated for SOA HETs. Figure 1 shows data for 'SOA HALL', which include data for both a commercial HET (BPT-4000) over its 1,220-2,150 sec $I_{s p}$ range $^{6}$, and the $12.5 \mathrm{~kW}$ HET (Hall Effect Rocket with Magnetic $\underline{\text { Shielding, or }}$ HERMeS) under co-development by NASA and JPL for the Solar Electric Propulsion Technology Demonstration Mission (SEP TDM) project over its intended 1,850-3,000 sec $I_{s p}$ range. ${ }^{7}$ Of note is that both thrusters essentially share a common maximum $F / P_{i n}$ vs. $I_{s p}$ curve with the BPT-4000 extending to lower $I_{s p}$, and HERMeS extending to higher $I_{s p}$, with a linear curve fit of these two data sets having a high (>0.95) correlation coefficient. Also plotted are 'SOA ION' data, which include those data sets from Table 1. Curve fits of both the SOA HALL and SOA ION data in Fig. 1 show a cross-over in $F / P_{i n}$ at about 2,600 seconds $I_{s p}$, with HETs having superior $F / P_{\text {in }}$ below 2,600 seconds, and ion engines having superior $F / P_{\text {in }}$ above 2,600 seconds - including at the intended HERMeS operating condition of 3,000 seconds.

In Fig. 2 the specific impulse vs. input power range for SOA thrusters are presented for comparison. These include the NEXT ion thruster, and the BPT-4000 and HERMeS HETs. While NEXT has a far larger demonstrated throttling range in both specific impulse and input power, it does so for the most part at a lower $F / P_{\text {in }}$ parameter.

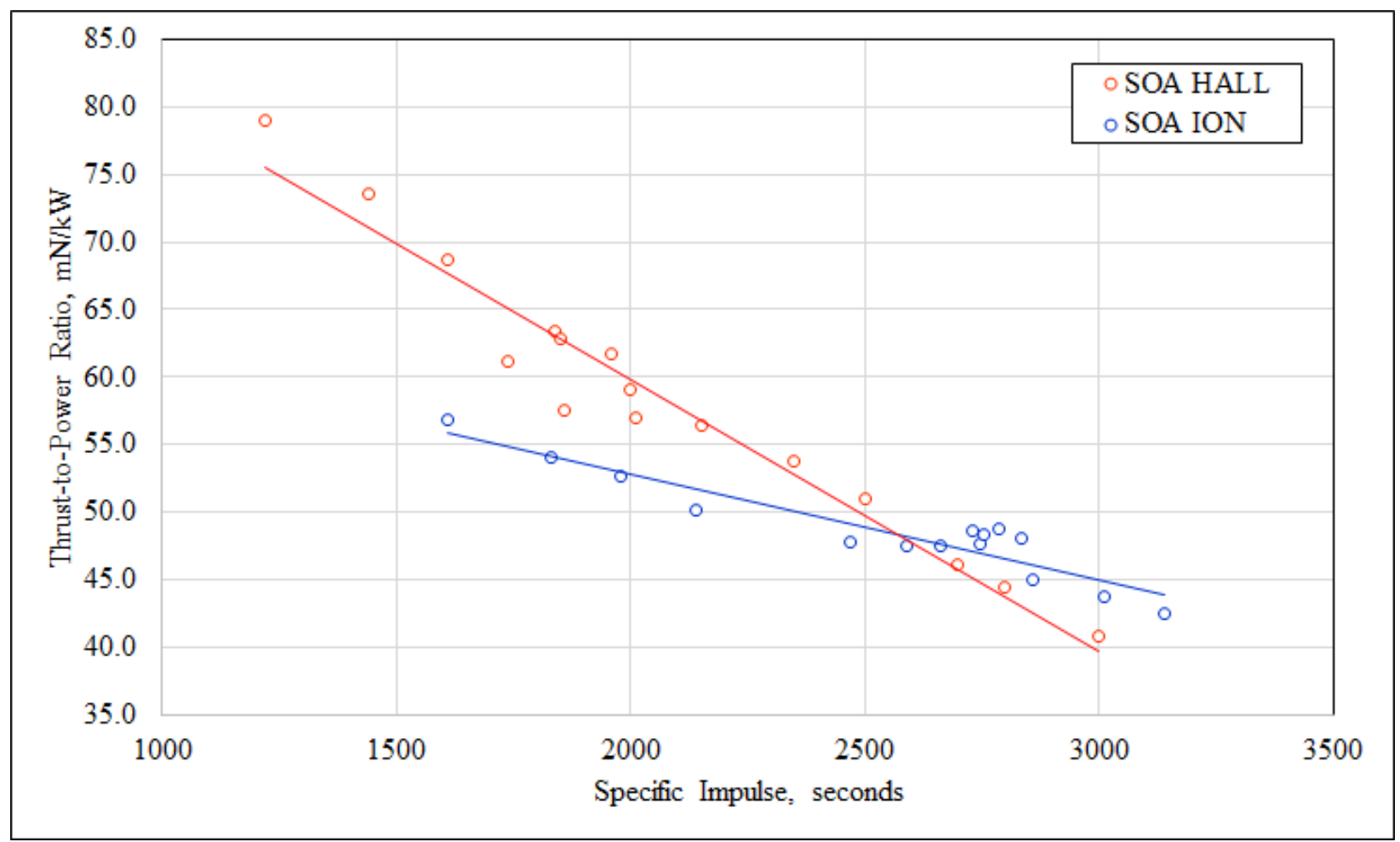

Figure 1. Thrust-to-Power ratio vs. Specific Impulse for SOA HALL (BPT-4000 and HERMeS HETs), as well as SOA ION (ion engine data from Table 1). Curve fits of data for both technologies indicate a crossover in $F / P_{\text {in }}$ at about 2,600 seconds.

Reference 1 provided a discussion of maximizing $F / P_{\text {in }}$ for ion engines. For xenon propellant the thrust-topower reduces to:

$$
F / P_{i n}=1.650 \times 10^{-3} \alpha \beta \frac{V_{b}{ }^{1 / 2}}{\left(V_{b}+\varepsilon_{i}\right)}
$$

Where thrust-to-power ratio is maximized as the thrust-loss correction factors, $\alpha$ and $\beta$, approach unity, and the beam voltage, $V_{b}$, and the discharge losses, $\varepsilon_{i}$, are minimized.

A potential effective means of maximizing ion engine $F / P_{\text {in }}$ is by development of a non-conventional design: the Annular Engine (AE). ${ }^{1}$ This design approach has several potential advantages: it should enable higher thrust density operation since the annular discharge chamber increases the effective anode surface area for electron collection as compared to a conventional cylindrically-shaped engine of equivalent beam diameter. This means that the engine 
would no longer be source limited (as apparent with conventional ring-cusp cylindrical discharges) and could operate much closer to the current extraction limit of the ion optics. This higher beam current capacity will naturally lower the discharges losses, $\varepsilon_{i}$, in addition to of course enabling higher power operation at lower $I_{s p}$. The annular optics design will allow one to fix the span and span-to-gap ratio to a relatively-low value, enabling reduced-dome, or zero-dome (flat) electrodes. Flat electrodes will inherently yield improved efficiencies by reducing or eliminating the thrust losses associated with off-axis vectoring, $\beta$, which occurs with conventional spherically-domed circular ion optics. The combination of reduced discharge losses and thrust losses enabled by the AE concept should boost the $F / P_{\text {in }}$ of ion engines.

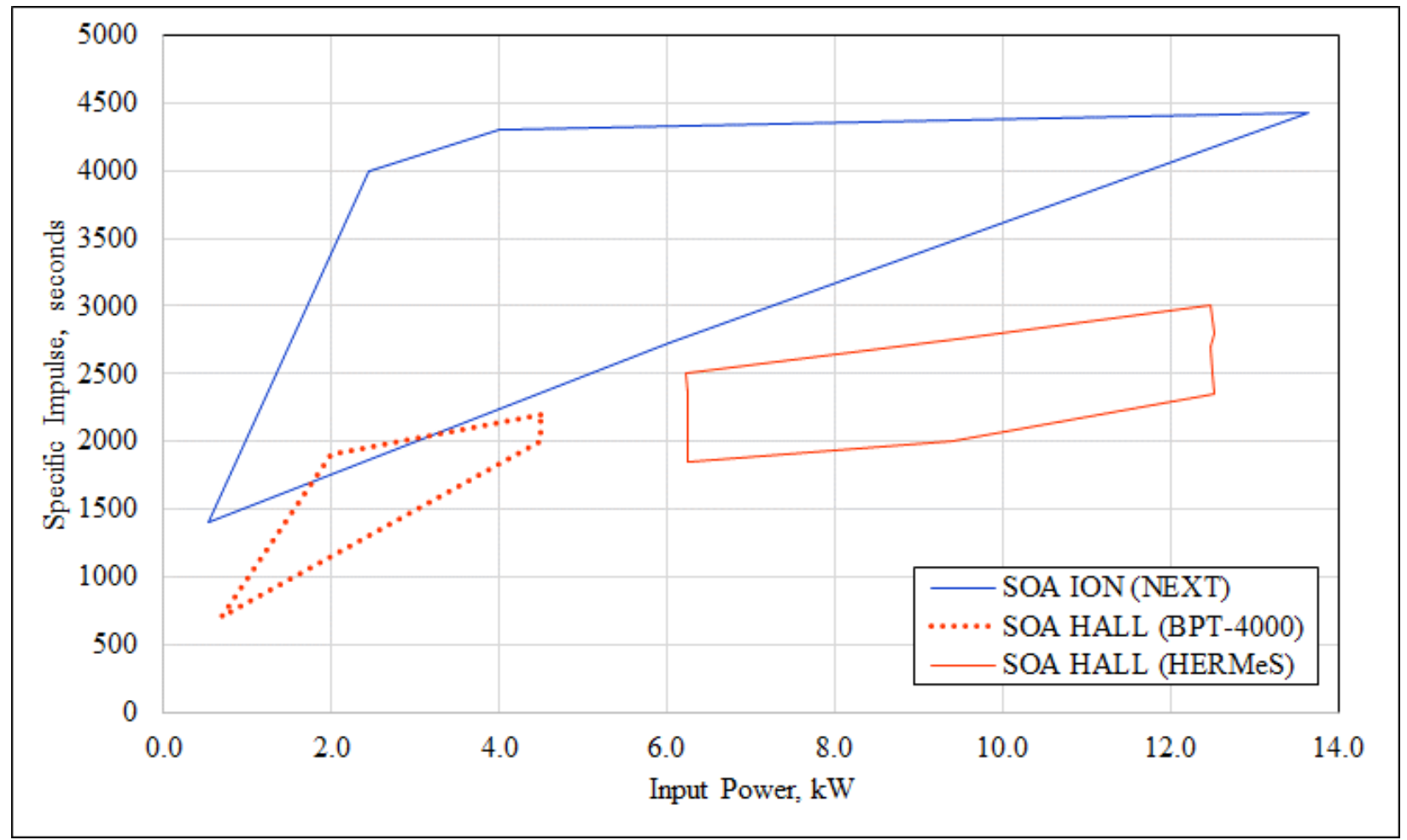

Figure 2. Specific Impulse vs. Input Power: SOA ION (NEXT, demonstrated); SOA HALL (BPT-4000, demonstrated, and HERMeS, intended throttle range for SEP TDM).

In addition, the $\mathrm{AE}$ flat optics allows for the practical implementation (simplified manufacturing) of carbon, in the form of pyrolytic graphite (PG), and the lifetime enhancements of this material. PG would yield an order-ofmagnitude improvement in life capability, which would more-than-offset the decrease in life caused by a potential increase in thrust density and thereby ensure long life. Development of annular ion optics also would simultaneously provide a design path for extending ion engine technology to very high power $(>100 \mathrm{~kW})$ at specific impulse values of interest $(\leq 3,000 \mathrm{sec})$ by demonstrating a means of scaling high-perveance ion optics to very large-areas, through the control of the span and span-to-gap ratio.

Figure 3 shows the curve fit of the SOA HALL data, from Fig. 1. In addition, projections of ('conventional') ion engine performance are given for a range of discharges losses, $\varepsilon_{i}$, from 80-150 W/A ['NEXT BETA ION']. The thrust-loss correction factors $\alpha$ and $\beta$ for these projections are assumed equivalent to those documented for the NEXT ion engine. ${ }^{7,8}$ With minor magnetic circuit modifications, higher throughput (current density) and lower

${ }^{7}$ For these calculations a fixed thrust-loss correction factor for doubly-charged ions, $\alpha$, is assumed equal to 0.9853 , corresponding to an (integrated) doubly-to-singly charged ion beam current ratio of 0.053 , which is typical of the NEXT ion thruster at full power. The thrust-loss correction factor due to beam divergence, $\beta$, is calculated assuming spherically domed electrodes, with a dependency on the net-to-total voltage ('R') ratio. This yields varying values from about 0.997 at high $I_{s p}$, down to 0.902 at low $I_{s p}$; values consistent with those measured from the NEXT thruster beam plume. 
discharge losses should be readily obtainable; at least to $150 \mathrm{~W} / \mathrm{A}$, and likely lower, to a limit of about $80 \mathrm{~W} / \mathrm{A} .{ }^{1}$ At 150 W/A, the cross-over point where the $F / P_{\text {in }}$ parameter for ion engines exceeds that for HETs is reduced from 2,600 seconds (for SOA engines) to about 2,300 seconds $I_{s p}$ - with further improvements in $\varepsilon_{i}$ lowering the crossover further.

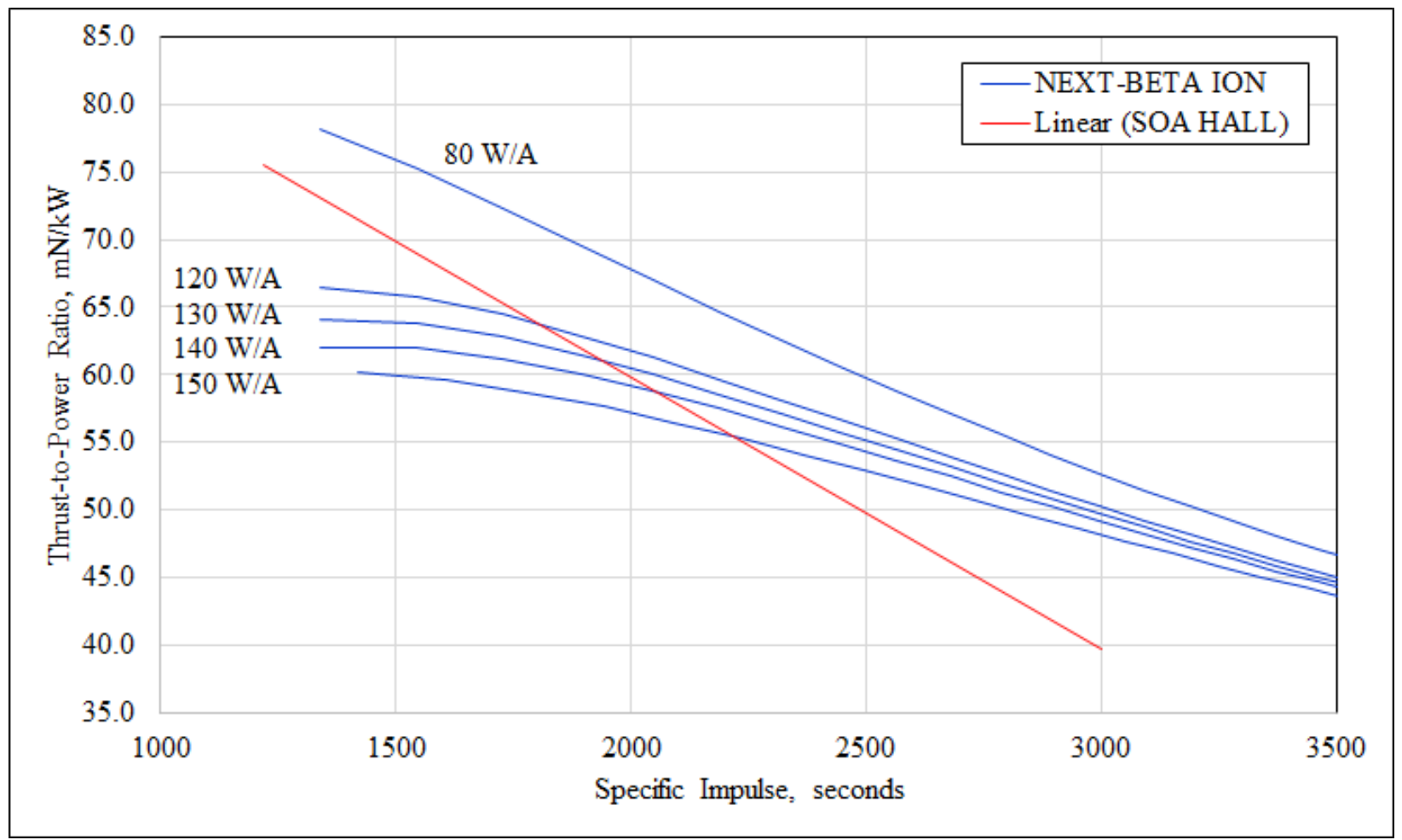

Figure 3. Thrust-to-power ratio vs. specific impulse. Comparison of (conventional) ion engine technology using NEXT ion optics over a range of assumed discharge losses vs. SOA HETs.

In Fig. 4, the curve fit of SOA HALL data are repeated from Fig. 1. However, the projections for ion engine performance, over the same range in discharge losses assumed in Fig. 3, now also assume a fixed high value for $\beta$ of 0.998 ['High-BETA ION'], consistent with the beam divergence documented previously for flat annular ion optics. ${ }^{5}$ In this instance, minor improvements in magnetic circuit design in combination with flat ion optics should drive the cross-over point where the $F / P_{\text {in }}$ parameter for ion engines exceeds that for HETs from 2,600 seconds down to about 1,800 seconds $I_{s p}$. Further improvements in $\varepsilon_{i}$ to about $120 \mathrm{~W} / \mathrm{A}$ would drive the $F / P_{i n}$ parameter for ion engines above HETs for all values of specific impulse. The combination of the ion engine $150 \mathrm{~W} / \mathrm{A} F / P_{\text {in }}$ curve from Fig. 3 and the ion engine $80 \mathrm{~W} / \mathrm{A} F / P_{\text {in }}$ curve from Fig. 4 bound the range of reasonable near-term performance expectations for the technology.

This publication discusses investigations into improving the $F / P_{\text {in }}$ parameter for ion engines, and in particular the development status of the AE concept. This work is conducted in collaboration with The Aerospace Corporation (TAC) and the University of Michigan. 


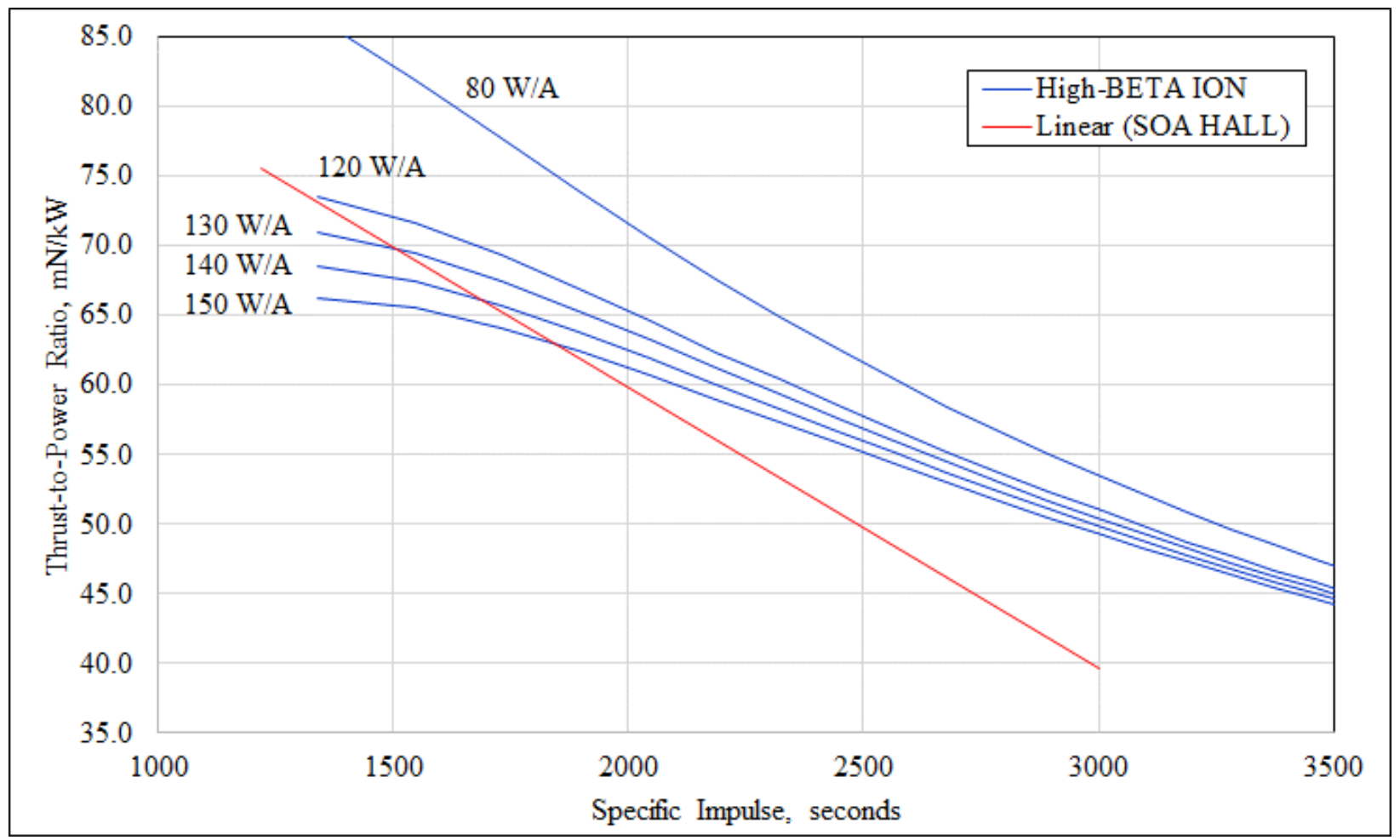

Figure 4. Thrust-to-power ratio vs. specific impulse. Comparison of (annular) ion engine technology employing flat ion optics over a range of assumed discharge losses vs. SOA HETs.

\section{High Thrust-to-Power Development Plan}

Two ion engine design paths may provide near-term opportunities for demonstration of high thrust-to-power ratio, and high thrust density operation:

1. Continued development of the AE concept; and

2. Demonstration of a (conventional) cylindrical-geometry ion engine derived from the NEXT ion thruster, but incorporating advanced-design ion optics to increase $\beta$ and a magnetic circuit intended to reduce $\varepsilon_{i}$ and inhibit source-limited operation.

The former provides an extensible pathway to higher power via the scalability of the annular ion optics, while the latter potentially provides a nearer-term technology product. These technology approaches are illustrated in Fig. 5. Both design paths are intended to yield a near-term focused technology product with superior performance and life in the 4-12+ $\mathrm{kW}$ power range for EOT applications.

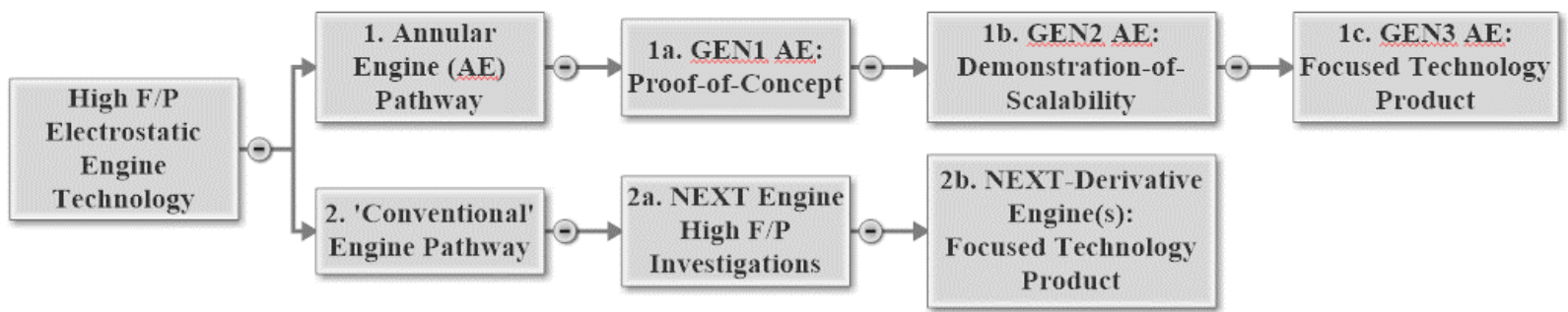

Figure 5. Technology development paths for high $F / P_{\text {in }}$ ion engine technology.

Details of recent work on the 'Conventional' engine pathway, NEXT engine high $F / P_{\text {in }}$ investigations (Fig. 5), can be found in a companion publication. ${ }^{9}$ That work is intended to conclude with sufficient design information to

6

American Institute of Aeronautics and Astronautics 
allow for the rapid development of one or more NEXT-derivative engine designs which can process high power and do so using discharge magnetics and ion optics which maximize the $F / P_{\text {in }}$ parameter.

The remainder of this publication discusses the status of the Annular Engine pathway; in particular the 'GEN2' ( $2^{\text {nd }}$-generation) $\mathrm{AE}$, built as a demonstration of the scalability of the concept, and forward $\mathrm{AE}$ plans [results from the 'GEN1', $1^{\text {st }}$-generation, AE have been previously reported $\left.{ }^{5}\right]$. This pathway is also intended to yield sufficient design information to allow for development of a focused technology product, GEN3 AE, targeting the 4-12+ $\mathrm{kW}$ power range operating at maximum $F / P_{i n}$, with bi-modal (high $F / P_{i n}$, and high $I_{s p}$ ) capability.

\section{GEN2 Annular Engine Development}

This section briefly discusses the design of the GEN2 AE, and performance expectations. Also included are preliminary test results of the discharge and the ion optics.

\section{A. Design and Performance Expectations}

To meet the objective of demonstrating scalability of the AE concept to high power - including scalability of the annular discharge chamber and ion optics, but also including demonstration of higher supportable discharge currents and beam current densities than SOA ion thrusters - requires the fabrication of a full-scale AE. This 'GEN2' AE was designed to be sufficiently large to operate in the $\sim 10$ 's of $\mathrm{kW}$ power range, and to assess whether or not the azimuthal and radial discharge and beam uniformity demonstrated with the $\sim 40 \mathrm{~cm}$ diameter GEN1 AE could be maintained using a single-cathode design.

The larger size would also provide the opportunity to address manufacturing, assembly, and test issues associated with larger-area PG electrodes, but was purposely limited to $\leq 66 \mathrm{~cm}$ annulus outside diameter (O.D.) so that a single (monolithic) panel construction technique could be employed for the ion optics. The GEN2 would also be scaled to ensure that there would be sufficient anode surface area to enable operation closer to the ChildLangmuir limit than is the case for conventional ion thrusters, while maintaining relatively-low discharge losses. With this scaling comes the opportunity to then assess whether or not higher discharge currents and higher beam current densities can be supported. The interior diameter (I.D.) of the annulus was also sized both to limit the optics span to a value comparable to that demonstrated with the GEN1 AE, approximately $14.4 \mathrm{~cm}$ diameter in the active area, but also sufficiently large to accommodate either a centrally-mounted neutralizer cathode assembly or integration of a centrally-mounted HET to investigate a hybrid engine configuration.

The GEN2 AE components and assembly are shown in Fig. 6. The AE has beam dimensions of approximately $65 \mathrm{~cm}$ O.D. and $36 \mathrm{~cm}$ I.D., yielding a total (annular) beam area $>2 X$ that of the NEXT ion thruster, with an anode area of approximately $4 \mathrm{X}$ that of the NEXT thruster. The discharge chamber employs a ring-cusp magnetic circuit using a reduced-energy-product (as compared to the GEN1 AE and prior NASA thrusters) magnet material. A significant degree of discharge modeling was performed with the assistance of University of Michigan to achieve the desired magnetic topology. Post-fabrication, the discharge chamber was subjected to magnetic field mapping to verify that the desired magnetic circuit was achieved.

The ion optics electrodes were machined at NASA from substrate nucleated PG panels. Each of the 2 electrodes contains 45,356 apertures. The electrodes were completed with $100 \%$ yield and zero defects. Upon inspection, the electrode geometry conformance-to-design exceeded that obtained with SOA conventional metal electrodes with apertures created using a photo-chemical etching process. The electrodes are flat, but incorporate radial ribs of thicker unperforated base material to increase the overall electrode stiffness, and are secured to mounting rings fabricated from carbon fiber-reinforced carbon ('carbon-carbon'). The mounting scheme for the electrodes incorporates flexures which allow for radial-motion under thermal load. The exterior dimensions (outer-envelope of plasma screen) for the laboratory-model GEN2 AE are approximately $76 \mathrm{~cm}$ diameter x $39 \mathrm{~cm}$ length, with a mass of approximately $34 \mathrm{~kg}$.

While the GEN2 AE is a laboratory-model experimental test article to evaluate scalability of the annular concept, and not a design solution to a specific propulsion application, it is of interest to note what the performance of such an $\mathrm{AE}$ size and configuration might yield. Figure 7 repeats the specific impulse vs. input power data for SOA ion engines and HETs from Fig. 2 but with inclusion of projections for the GEN2 AE. For the GEN2 AE: a value for the thrust-loss correction factor $\alpha$ was assumed to be equivalent to that documented for the NEXT ion engine; the thrust-loss correction factor $\beta$ was assumed to be modestly improved from that documented for the NEXT ion engine, varying from about 0.993 at high $I_{s p}$ down to about 0.933 at low $I_{s p}$; discharges losses, $\varepsilon_{i}$, were conservatively assumed to be $200 \mathrm{~W} / \mathrm{A}$; and a perveance per-unit-area and total maximum voltage equivalent to that of the NEXT ion thruster were assumed. The engine was also assumed to be source (anode area) limited to about 
140 Amperes discharge current (estimated based upon the product of the maximum supportable discharge current for the NEXT ion thruster and the anode area ratio of the GEN2 AE-to-NEXT ion thruster), corresponding to a maximum beam current of about 18 Amperes.
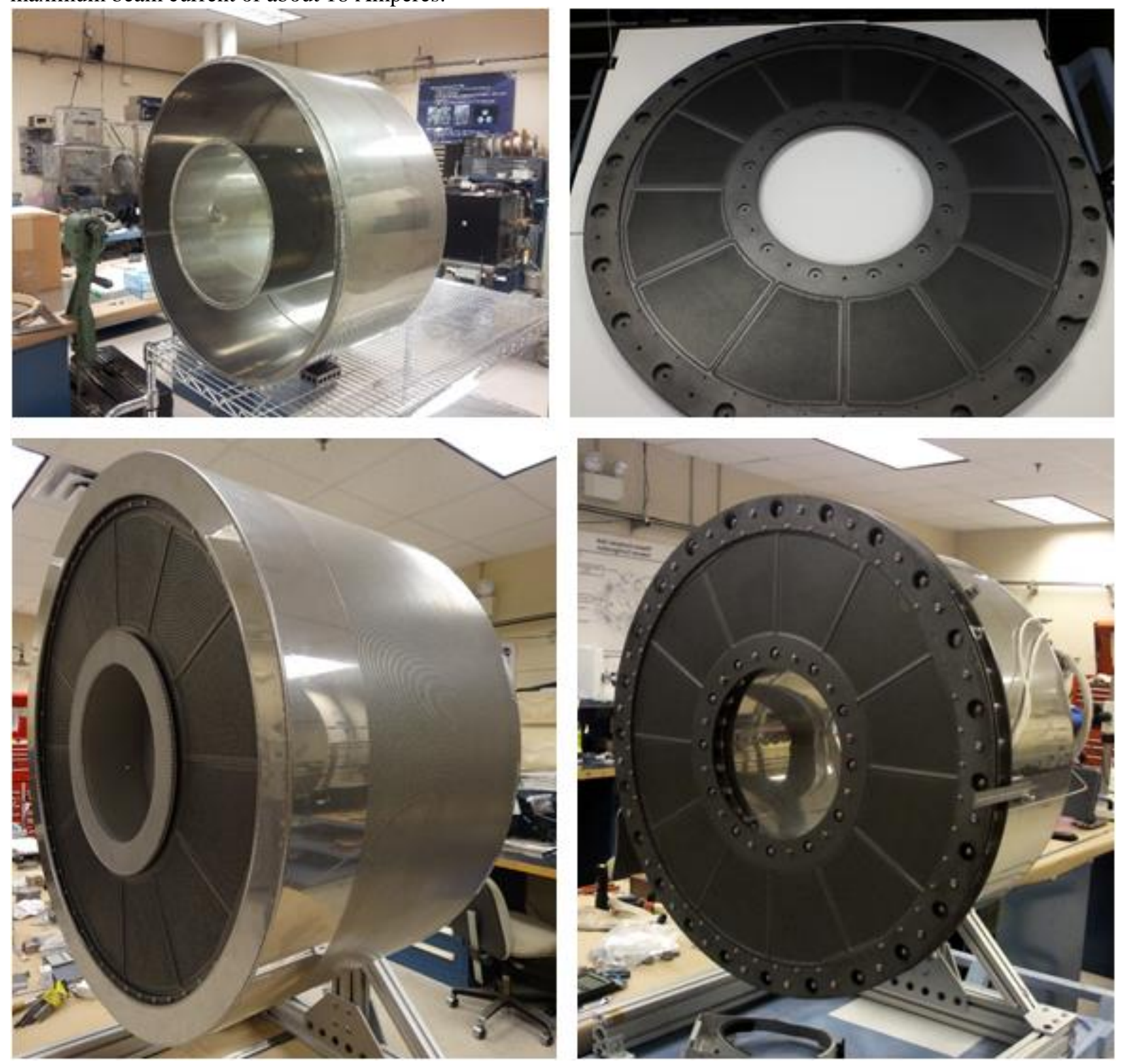

Figure 6. Images of GEN2 (65 cm outer diameter) Annular Engine hardware, from top left, clockwise: annular discharge chamber, sans magnets, undergoing assembly; pyrolytic graphite electrodes with carboncarbon stiffener rings; ion optics assembly integrated with discharge chamber; assembled engine with plasma screen, sans neutralizer assembly. The ion optics have approximately $2200 \mathrm{~cm}^{2}$ of beam-extraction area.

In this instance the $\mathrm{AE}$ performance envelope for the most part subsumes all of the other EP thruster technology options. A peak input power of about $37 \mathrm{~kW}$ would be anticipated. Assuming that the discharge magnetic circuit can be modified such that the engine is ion optics limited, and not source limited, the peak input power can be increased to about $56 \mathrm{~kW}$, corresponding to a discharge current of about 216 Amperes and a maximum beam current of 28 Amperes. 


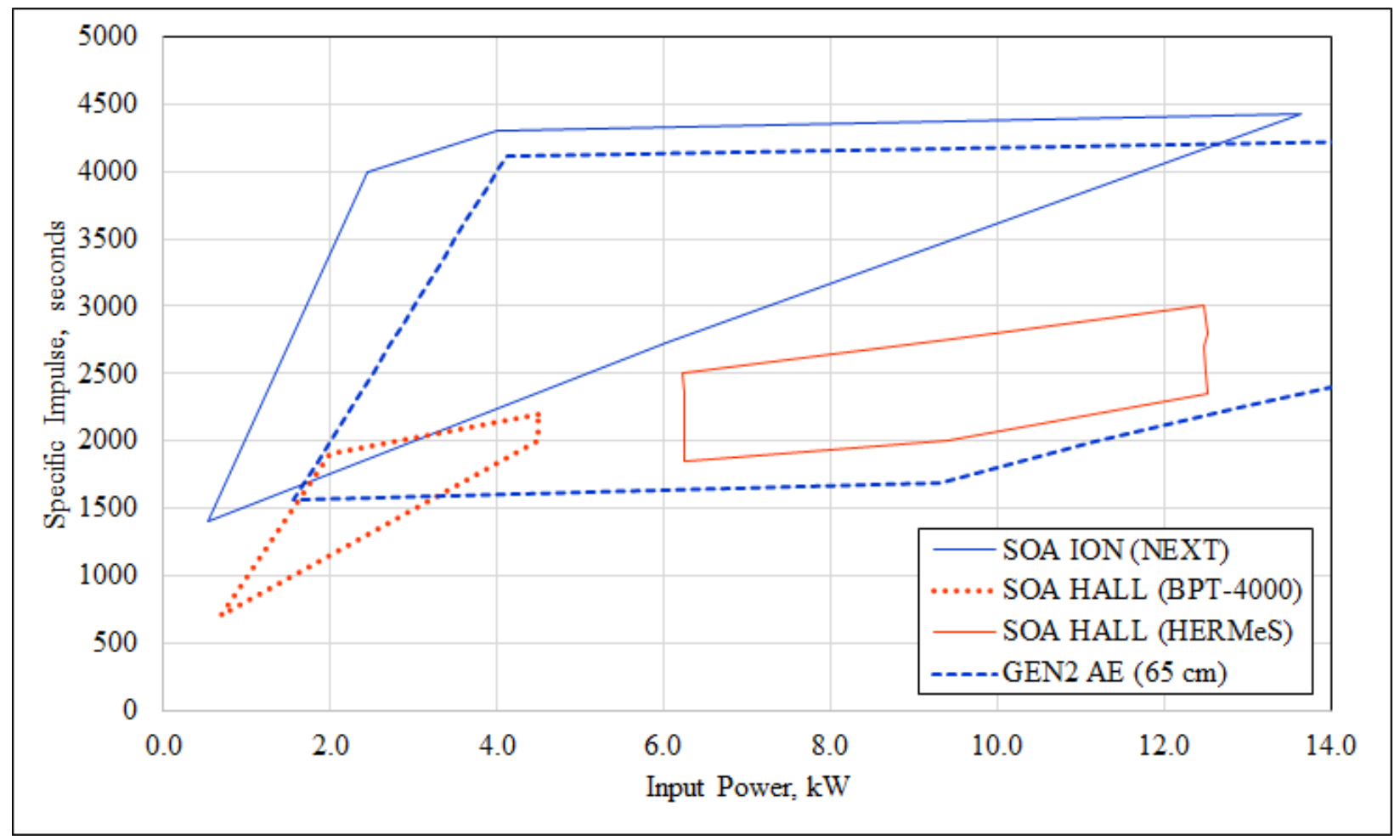

Figure 7. Specific Impulse vs. Input Power: SOA ion engine; SOA HETs; and anticipated performance of GEN2 AE.

\section{B. Discharge Chamber Tests}

As is done by (NASA) standard convention, upon completion of fabrication of the discharge chamber it was subjected to a series of tests under conditions simulating beam extraction to: verify discharge stability; document discharge plasma azimuthal and radial uniformity; and estimate discharge losses. The results of these tests are discussed in detail in a companion publication ${ }^{10}$ but some of the more salient results as they pertain to the operation of the AE are briefly discussed here. All testing described in this publication was performed at The Aerospace Corporation (TAC) in EP2 chamber, a 2.4-m-diameter by 9.8 -m-long cryopumped vacuum chamber with an effective pumping speed on Xe of about $290 \mathrm{~kL} / \mathrm{s}$.

Figure 8 shows images of the discharge chamber in the TAC facility. In the left-hand photo the discharge chamber is shown with a cathode-potential grid-plate attached to the downstream end. The grid-plate consists of a single perforated metal screen used to simulate a set of ion optics, with an open area fraction approximately equal to the neutral transparency of high perveance ion optics, electrically isolated from the (anode potential) discharge chamber.

The grid-plate contained an array of embedded probes at the 12-, 4-, and 8-o'clock positions to measure azimuthal and radial current densities at the plane of the grid-plate. In addition, 3 Langmuir probes were installed through the grid-plate, penetrating midway into the discharge chamber to assess azimuthal uniformity in the midvolume of the discharge, with one of the probes located just off-axis of the main discharge cathode assembly (located at 12-o'clock) to sample the near-cathode plume plasma. The right-hand photo in Fig. 8 shows operation of the discharge chamber. A high-speed ( $20 \mathrm{kHz}$ frame-rate) digital camera was also employed to examine discharge instabilities. 

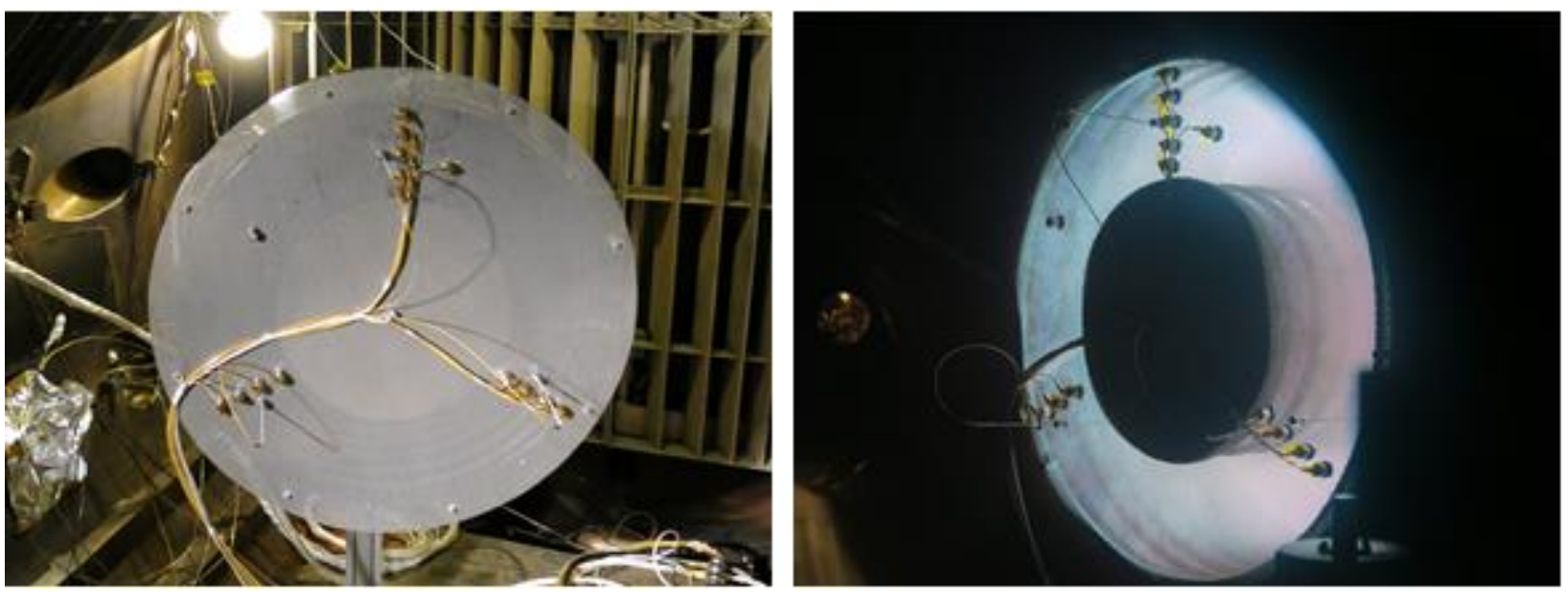

Figure 8. Images of GEN2 (65 cm outer diameter) Annular Engine hardware, from left-to-right: annular discharge chamber with high-transparency grid-plate and embedded probes on downstream end of discharge chamber, inside Aerospace Corporation's EP2 chamber in preparation for discharge testing; annular discharge chamber in vacuum undergoing simulated beam extraction tests.

The discharge chamber tests were somewhat limited in scope and duration by two constraints: an intermittent thermally-induced short between the grid-plate and the anode potential discharge chamber; and the power console used for these tests had a discharge power supply with a maximum current capacity of only about 36 Amperes. These constraints limited the peak discharge power to about $1440 \mathrm{~W}$, or about 7.2 Amperes beam current equivalent at $200 \mathrm{~W} / \mathrm{A}$. Despite this, the tests were able to successfully demonstrate the following with the GEN2 AE discharge chamber:

1. Extremely-stable discharge operation over a broad range in discharge currents, from as low as 3.0 Amperes up to the power supply limit of 36 Amperes. Interestingly, the minimum sustainable discharge current was about 3.0 Amperes, below which the cathode would occasionally extinguish due to insufficient self-heating. This minimum discharge current is significantly lower than that demonstrated with the NEXT ion thruster (approximately 7.5 Amperes), and the GEN1 AE (10-13 Amperes) - despite the fact that all 3 engines were tested with an identical cathode design. The 7.5 Amperes limit observed with the NEXT thruster was originally interpreted as a cathode thermal limit; however it now appears that these differences are attributable to a discharge stability criterion associated with magnetic impedance, with the GEN2 having the lowest magnetic impedance, NEXT being intermediate, and GEN1 AE having the highest magnetic impedance.

2. In general, the discharge could not be driven into any instability that could be observed with the probe diagnostics or the high-speed camera. Several ignitions of the discharge, however, were captured with the highspeed camera, one of which is shown in a sequence of images in Fig. 9. As indicated during ignition the discharge would propagate uniformly from the discharge cathode assembly (located at the 12 o'clock position at the rear of the discharge chamber in the radial-center of the annulus) azimuthally through the discharge in both directions and coming to a uniform plasma density in about 900 microseconds.

3. Discharge plasmas highly uniform in the radial and azimuthal directions were observed for the GEN2 discharge chamber using this single hollow cathode design. For a given radial position, the current densities were typically within about $10 \%$ of the mean at different azimuthal positions ${ }^{10}$; results consistent with those documented previously for the GEN1 AE discharge. ${ }^{11}$

4. With increasing discharge power the radial current density profiles measured from the array of probes at 12-, 4and 8-o'clock positions shown in Figs. 8 and 9 tend to merge in shape function and magnitude, indicating homogenization with increasing cathode emission current. 

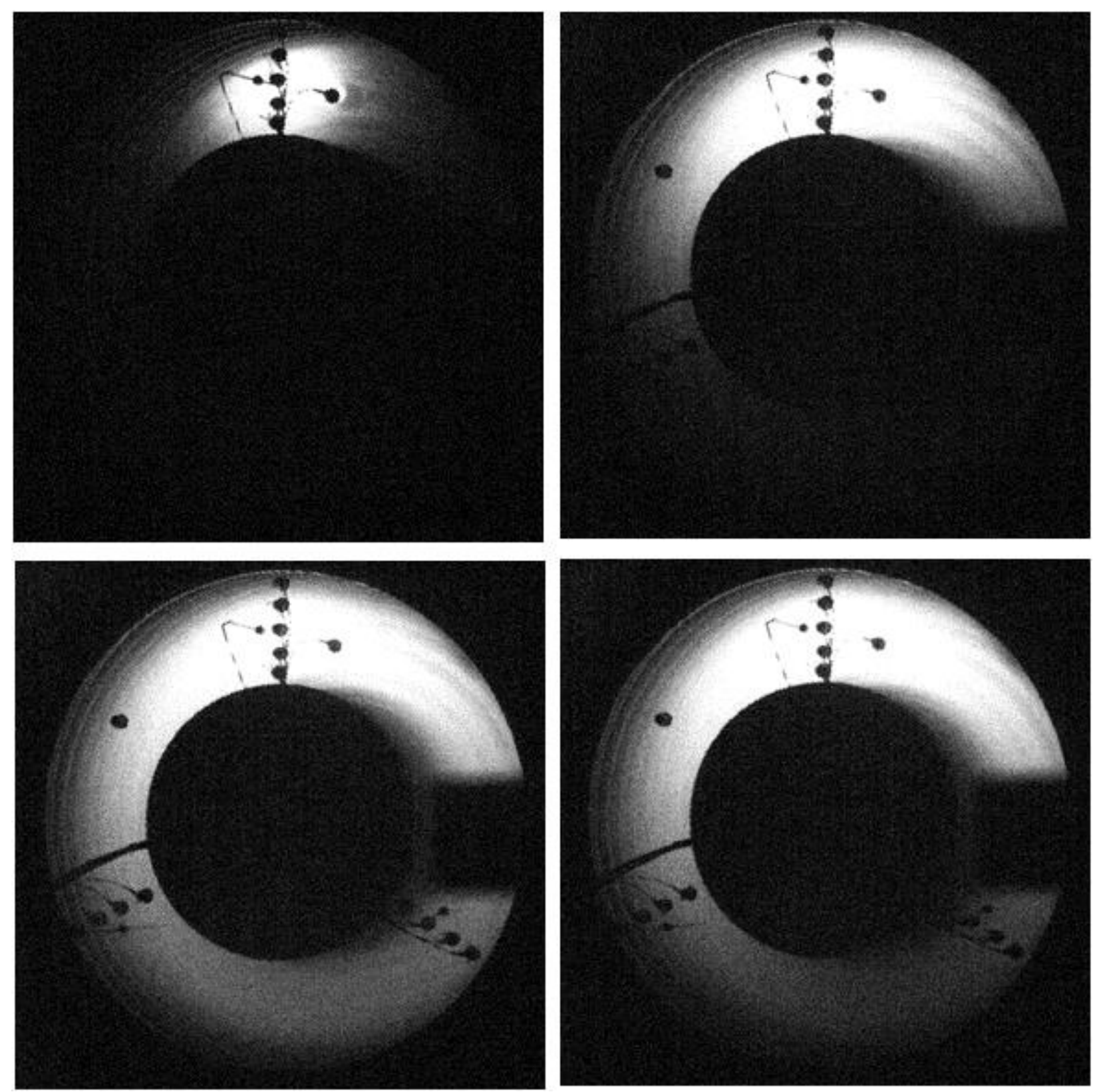

Figure 9. Time-lapse of GEN2 annular discharge ignition obtained from high-speed camera, clockwise from top-left image in 300 microsecond increments. Discharge cathode assembly is at 12-o'clock position in the annulus. Rectangular 'shadow' at 3-o'clock across the annulus is due to ground support equipment blocking the camera field-of-view.

5. The maximum current density (measured at the plane of the downstream grid-plate) along a radius for a given azimuthal location increased monotonically with increasing discharge power. This is shown in Fig. 10, a plot of maximum current density vs. discharge power for all 3 azimuthal locations. As indicated, the maximum current densities vary from about $2 \mathrm{~mA} / \mathrm{cm}^{2}$ at about $740 \mathrm{~W}$ to about $5.5 \mathrm{~mA} / \mathrm{cm}^{2}$ at $1440 \mathrm{~W}$; similar to those values measured for GEN1 AE when the discharge power is adjusted for the difference in beam areas. 


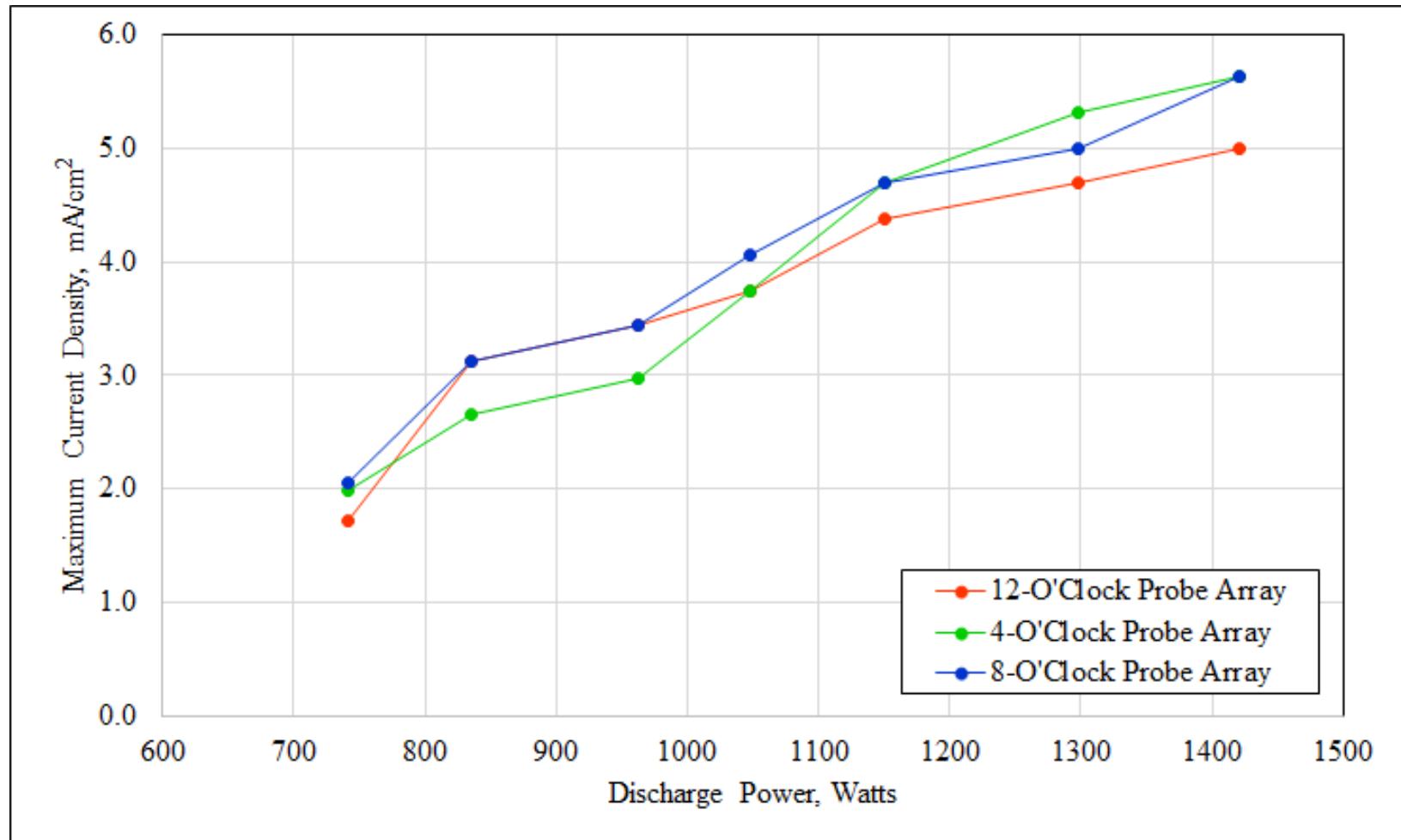

Figure 10. GEN2 AE discharge maximum current density vs. discharge power measured at the downstream grid-plate for 3 azimuthal locations. Discharge cathode assembly is centrally-located along the 12-o'clock position.

6. For purposes of assessing discharge electrical efficiency, the grid-plate was biased $-20 \mathrm{~V}$ with respect to cathode common and the ion saturation current to the plate was measured. This was repeated over a range of discharge input powers, the results of which are shown in Fig. 11 - a plot of ion saturation current to the biased grid-plate as a function of discharge power. The ion production is fairly linear with a modest roll-off at high discharge power, with the ion saturation current varying from about 1 Amperes at $300 \mathrm{~W}$ to about 6.5 Amperes at $1440 \mathrm{~W}$. These results were converted into estimated discharge losses, $\varepsilon_{i}$, anticipated for the AE during operation with beam extraction. Using the methodology described in Ref. 12 the ion saturation current was adjusted to account for the ion transparency of the ion optics, yielding Fig. 12, a plot of estimated discharge losses vs. simulated beam current for the GEN2 AE. As indicated the discharge losses decrease with increasing beam current, as expected, asymptotically reaching about $250 \mathrm{~W} / \mathrm{A}$. While not as efficient as desired the results are satisfactory for the initial magnetic circuit iteration.

The results of testing the GEN2 discharge chamber indicated stable discharge operation and relatively-uniform plasma densities for such a large plasma discharge, and satisfactory results relative to expected discharge efficiency for operation with beam extraction. The discharge was subsequently modified as required to operate under highvoltage conditions integrated with ion optics, including retrofitting of a plasma screen.

\section{Operation with Beam Extraction}

Subsequent to completion of the discharge chamber tests the ion optics assembly was completed and mated to the anode, and the engine assembly was finished including installation of plasma screen surfaces and the neutralizer cathode assembly in preparation for testing. The GEN2 AE test was to have included the integration of a new 20 $\mathrm{kW}$ Power Console, but it was not ready in time for this test. The new console, which is a divergence from the design employed by the NEXT technology project, has a higher current rated discharge power supply (250 Amperes vs. 40 Amperes) and a 


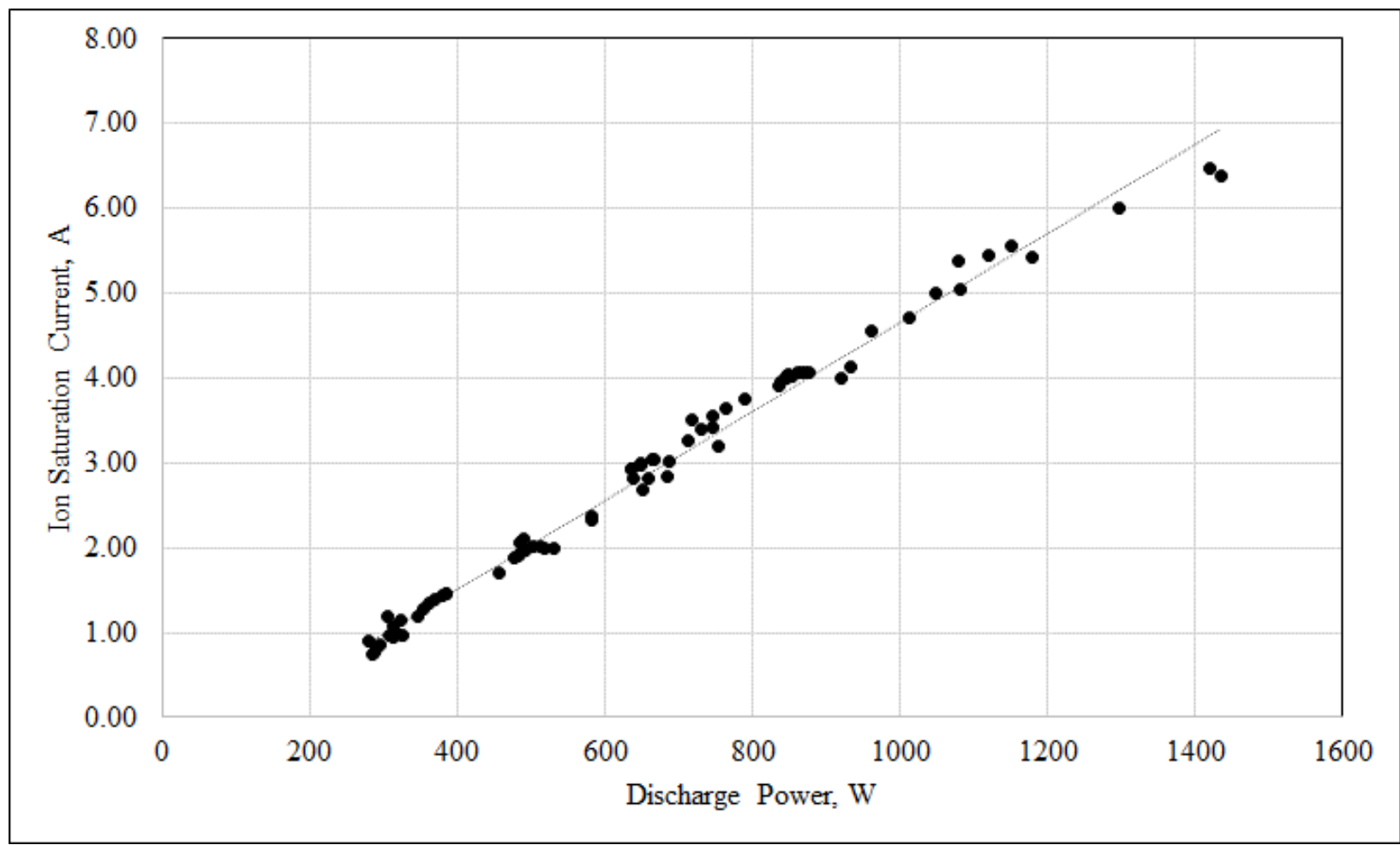

Figure 11. Ion saturation current measured to downstream grid-plate vs. discharge power; GEN2 AE discharge chamber simulated beam extraction test.

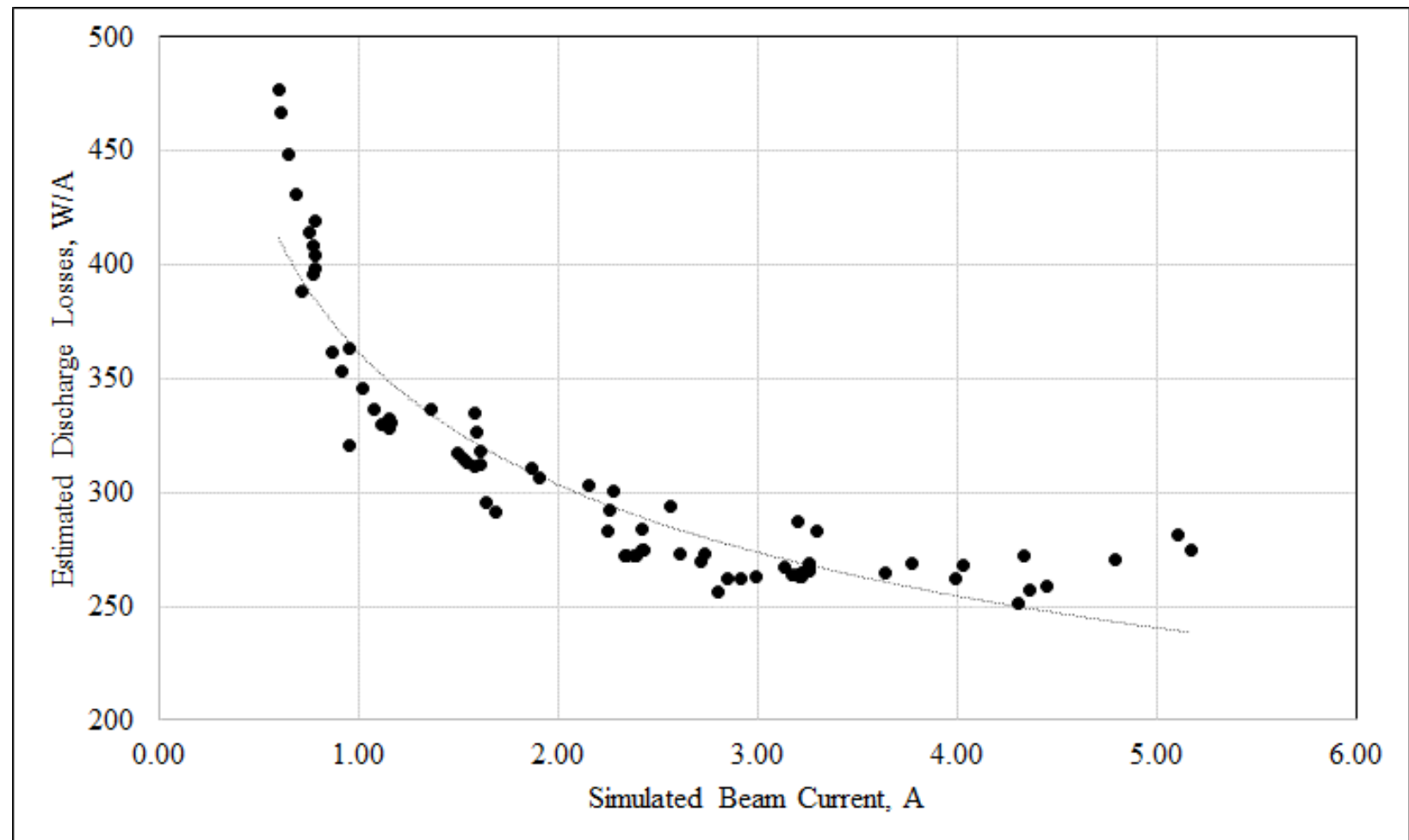

Figure 12. Estimated discharge losses vs. simulated beam current; GEN2 AE discharge chamber simulated beam extraction test. 
higher current beam power supply (20 Amperes@1 kV vs.10 Amperes@ 2 kV). These and other alterations in the power circuits will provide the necessary capability to characterize the GEN2 AE up to $20 \mathrm{~kW}$ with particular emphasis on operation at lower $I_{s p}$.

At the time of this publication only a very-modest level of testing of the full engine with beam extraction has been completed. However, the ion optics electrostatic design was validated to a degree, and successful ion beam extraction was demonstrated. Figure 13 shows two images of the AE operating with beam extraction; both a sideview showing the beam propagation, and a head-on view directly looking into the discharge chamber.
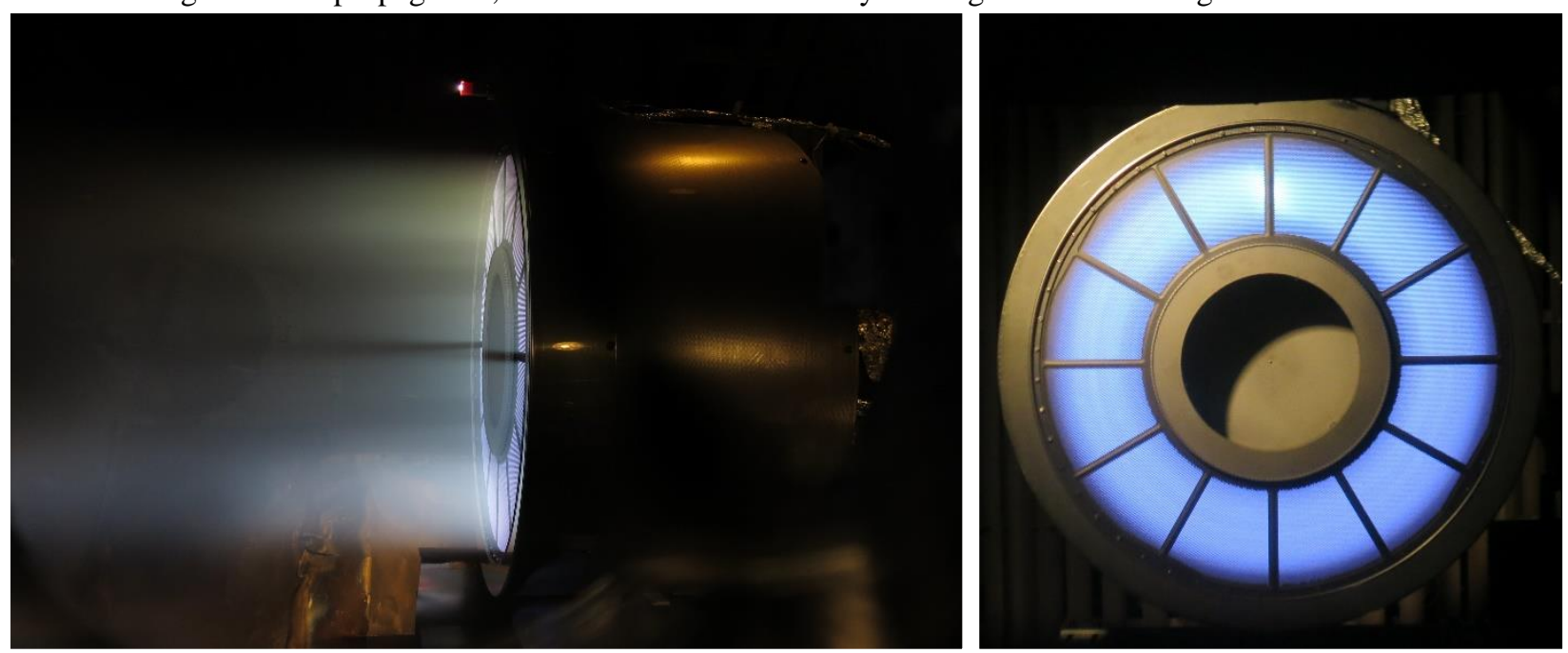

Figure 13. Images of GEN2 (65 cm outer diameter) Annular Engine beam extraction tests, left-to-right: sideview showing beam propagation; head-on view of engine. Neutralizer cathode assembly can be seen at 12o'clock position (left image) and is cropped (right image) due to beam target surface in camera field-of-view.

Some observations and issues with the laboratory-model hardware relative to the beam extraction tests are summarized here:

1. Intermittent interelectrode shorting occurred due to the presence of some remaining manufacturing debris created from the beam aperture milling process, the frequency of which reduced with operating time as the optics 'cleaned up' in vacuum. This may have been exacerbated by the transport of the hardware from NASA to TAC. This was subsequently addressed by a full-inspection and cleaning of the PG electrode surfaces, and is not anticipated to be an endemic issue with the electrode material or manufacturing process.

2. A recurrent thermally-induced short between the ion optics accelerator electrode potential and anode potential occurred. This was identified as a diametric clearance issue between the anode-potential optics mounting ring that mates to the discharge chamber and accelerator electrode potential optics shadow shields. This has since been addressed.

3. Some anomalous behavior of the accelerator electrode impingement current (or, drain current) was noted, including both its magnitude (high, $\sim 1-2+\%$ of the beam current) and its sensitivity to discharge parameters and applied accelerator electrode potential. Three mechanisms were identified as potential causes for the high accelerator current. These include:

a. The large area of unperforated (without beam apertures) accelerator potential surface on the downstream plane of the electrode exposed to the charge-exchange plasma. This included the exposed electrode surface within the inside diameter of the aperture area (about $264 \mathrm{~cm}^{2}$ ), the exposed electrode surface outside the diameter of the aperture area (about $262 \mathrm{~cm}^{2}$ ), and the exposed electrode surface on the 'stiffener' ribs (about $85 \mathrm{~cm}^{2}$ ), all totaling $611 \mathrm{~cm}^{2}$. This solid area is equal to about $79 \%$ of the total surface of a NEXT ion thruster accelerator electrode, and therefore may contribute to the observed high baseline current. This can be mitigated by extending the coverage of the plasma screen front masks - both the annulus mask by increasing its O.D., and the exterior front mask by decreasing its I.D. - to cover more of the exposed and unperforated accelerator electrode outside the active beam extraction area to block the collection of charge-exchange current.

b. The potential presence of a 'cathode-jet' - a highly-collimated plasma from the discharge cathode, particularly at conditions of high emission current-to-cathode flow rate experienced at high propellant 
efficiency. This may result in a locally-peaked plasma density at the ion optics in a very small region immediately downstream of the cathode, resulting in a high accelerator impingement current. This mechanism was suggested by the high sensitivity of the accelerator impingement current to cathode flow rate. In addition, upon engine assembly, the discharge cathode was azimuthally aligned with the electrode stiffener ribs at 12-o'clock [see Fig. 13, head-on view, the electrode stiffener ribs at 12-o'clock directly occult the discharge cathode in the rear of the discharge chamber]. Prior to test termination this hypothesis was checked by rotating the ion optics 15 -degrees with respect to the discharge chamber such that the discharge cathode would then be aligned with the center of one of the perforated electrode panels. The engine was retested and it was found that the magnitude of the accelerator impingement current dropped by as much as $2 \mathrm{X}$ at equivalent operating conditions, albeit it was still higher than desired. The approach going forward is to maintain the present cathode - optics orientation [15-degree rotation from that shown in Fig. 13]. In addition, a potential modification of the magnetic circuit in the region of the discharge cathode is under consideration to improve diffusion of the cathode plasma.

c. Upon post-test engine disassembly and inspection, a third potential mechanism causing high accelerator impingement current was identified. The accelerator electrode flexure assemblies on the I.D. of the ion optics annulus had a direct line-of-sight radially to the discharge chamber plasma, because of the vacuum gap between the cathode potential screen electrode and the anode potential discharge chamber. This allowed the accelerator electrode mounting flexures to 'see' the discharge plasma and directly collect discharge ions. This error is being corrected by electrically shielding the accelerator potential surfaces in the region of the vacuum gap with a cathode potential barrier.

The aforementioned engine modifications are presently being implemented. The degree to which identified mechanisms were contributory to the high impingement current will be the subject of additional testing.

\section{Forward Work}

Figure 5 illustrated the intended parallel technology development paths for high $F / P_{\text {in }}$ ion engine technology. The objective of this effort is of course to demonstrate and evaluate the capability of ion engine technology to support operation at high $F / P_{\text {in }}$ exceeding SOA EP thrusters in the 4-12+ $\mathrm{kW}$ input power range.

The near-term goal is to validate the annular engine configured with high- $\beta$ (flat or reduced dome) carbon-based ion optics as a high $F / P_{\text {in }}$ option over a wide operational envelope. This involves hardware rework of both the GEN1 and GEN2 annular engines (optics and magnetics) for optimum consistency with the goal. Returning to test GEN1 AE is value-added as it is closer in power range to the intended technology product. Both engines will subsequently be fully-characterized to document performance and maximum $F / P_{i n}$ characteristics.

The mid-term goal is then to optimize ion engine technology for high $F / P_{\text {in }}$ operation. This includes the design, fabrication, and performance characterization of a GEN3 AE, incorporating lessons learned, as a focused technology product with a 4-12+ kW target operating range, with bi-modal (high $F / P_{i n}$, and high $I_{s p}$ ) capability. In parallel, one or more NEXT-derivative $40 \mathrm{~cm}$ engine concepts, incorporating improved optics to increase $\beta$ and alternative magnetics to inhibit source limited operation, will be designed, fabricated, and tested with the same intended power range and bi-modal capability.

\section{Summary}

Despite more than 50 years of research and development in ion engine technology these devices were never optimized for Earth orbit transfer operations where maximizing thrust-to-power $\left(F / P_{i n}\right)$ is the critical metric. However, improvements in the ion engine $F / P_{\text {in }}$ parameter may yield higher performance than any other EP technology in the 4-12+ $\mathrm{kW}$ power range, over the broadest obtainable range in specific impulse.

A potential means of maximizing ion engine $F / P_{\text {in }}$ is by development of a non-conventional design; the Annular Engine (AE). Annular optics allow one to fix the span and span-to-gap ratio to a relatively-low value, enabling reduced-dome, or flat, electrodes, which will yield improved efficiencies by reducing or eliminating the thrust losses associated with off-axis vectoring inherent with spherically-domed circular ion optics. A combination of reduced discharge and thrust losses has the potential to lower the cross-over point where ion engines exceed the $F / P_{\text {in }}$ of SOA Hall thrusters from 2,600 seconds down to below 1,800 seconds $I_{s p}$.

Two ion engine design paths may provide near-term opportunities for demonstration of high thrust-to-power ratio: continued development of the $\mathrm{AE}$ concept, which has the potential to yield the highest $F / P_{\text {in }}$; and 
(conventional) designs derived from the $40 \mathrm{~cm}$ NEXT ion thruster, which may yield a faster technology product. The status of the AE pathway; specifically the development of a $65 \mathrm{~cm}$ outer diameter $2^{\text {nd }}$-generation ('GEN2') $\mathrm{AE}$, built as a demonstration of the scalability of the concept, was discussed. Discharge chamber tests were successfully concluded, with excellent discharge stability over a broad discharge current range, yielding good plasma uniformity. Manufacturing of large-area high-perveance-design carbon ion optics were subsequently completed, integrated with the AE discharge chamber, and beam extraction testing of the AE has been initiated.

Forward work was identified, with both the $\mathrm{AE}$ and conventional pathways directed to provide a focused technology product designed for operation in the $4-12+\mathrm{kW}$ power range with the highest thrust-to-power possible, with bi-modal (high $F / P_{i n}$, and high $I_{s p}$ ) capability.

\section{Acknowledgments}

The support of Mr. Jesus Lopez of Sierra Lobo, Inc. for design assistance and manufacturing of the pyrolytic graphite ion optics and Mr. Kevin McCormick of NASA GRC for thruster design assistance, fabrication, and assembly is gratefully acknowledged. This work was supported under the GRC Center Innovation Fund program sponsored by NASA's Office of Chief Technologist, and The Aerospace Corporation's Independent Research and Development Program.

\section{References}

${ }^{1}$ Patterson, M.J., et al., "Development Status of High-Thrust Density Electrostatic Engines," AIAA Paper No. 2014-3422, 50th Joint Propulsion Conference, July, 2014

${ }^{2}$ Patterson, M.J. and Rawlin, V.K., "Performance of 10-kW Class Xenon Ion Thrusters," AIAA Paper No. 88-2914, 24 ${ }^{\text {th }}$ Joint Propulsion Conference, July, 1988

${ }^{3}$ Patterson, M.J., "Low-Isp Derated Ion Thruster Operation," AIAA Paper No. 92-3203, 28th Joint Propulsion Conference, July, 1992

${ }^{4}$ Patterson, M.J., "NEXT Study of Thruster Extended Performance (NEXT STEP)," AIAA Paper No. 2006-4664, 42nd Joint Propulsion Conference, July, 2006

${ }^{5}$ Patterson, M.J., Foster, J.E., Young, J.A., and Crofton, M.W., “Annular Engine Development Status,” AIAA Paper No. 2013-3892, 49th Joint Propulsion Conference, July, 2013

${ }^{6}$ Welander, B., Carpenter, C., de Grys, K., Hofer, R.R., Randolph, D.H., and Manzella, D.H., "Life and Operating Range Extension of the BPT-4000 Qualification Model Hall Thruster," AIAA Paper No. 2006-5263, 42nd Joint Propulsion Conference, July, 2006

${ }^{7}$ Hofer, R.D., et al., "Design Methodology and Scaling of the $12.5 \mathrm{~kW}$ HERMeS Hall Thruster for the Solar Electric Propulsion Technology Demonstration Mission," JANNAF-2015-3946, presented at the 62nd JANNAF Propulsion Meeting, Nashville, TN, June, 2015

${ }^{8}$ Pollard, J.E, Diamant, K.D., Crofton, M.W., Patterson, M.J., and Soulas, G.C., "Spatially-Resolved Beam Current and Charge-State Distributions for the NEXT Ion Engine" AIAA Paper No. 2010-6779, 46 ${ }^{\text {th }}$ Joint Propulsion Conference, July, 2010

${ }^{9}$ Thomas, R.E., et al., "Advancements in the Demonstration of High Thrust to Power Ion Engine Technology," proposed for presentation at the $51^{\text {st }}$ Joint Propulsion Conference, July 2015

${ }^{10}$ Arthur, N.A, et al., "Characterization of Discharge Uniformity and Performance via Simulated Beam Extraction of a $65 \mathrm{~cm}$ Annular Ion Engine," proposed for presentation at the 51 $1^{\text {st }}$ Joint Propulsion Conference, July 2015

${ }^{11}$ Shastry, R., Patterson, M.J., Herman, D., Foster, J.E., "Current Density Measurements of an Annular-Geometry Ion Engine," AIAA Paper No. 2012-4186, 48 ${ }^{\text {th }}$ Joint Propulsion Conference, July, 2012

${ }^{12}$ Brophy, J.R., "Simulated Ion Thruster Operation without Beam Extraction,” AIAA Paper No. 90-2655, July 1990. 